\title{
Factors affecting residents transition from long term care facilities to the community: a scoping review
}

\author{
Shannon Freeman ${ }^{1 *}$, Kristen Bishop ${ }^{2}$, Lina Spirgiene ${ }^{3}$, Erica Koopmans ${ }^{4}$, Fernanda C. Botelho ${ }^{5}$, Trina Fyfe ${ }^{6}$,
} Beibei Xiong ${ }^{4,7}$, Stacey Patchett ${ }^{8}$ and Martha MacLeod ${ }^{1}$

\begin{abstract}
Background: Long-term care facilities (LTCFs) are often places where persons with complex health needs that cannot be met in a community setting, reside and are cared for until death. However, not all persons experience continuous declines in health and functioning. For some residents who experience improvement in personal abilities and increased independence, transition from the LTCF to the community may be an option. This scoping review aimed to synthetize the existing evidence regarding the transition process from discharge planning to intervention and evaluation of outcomes for residents transitioning from LTCFs to the community.

Methods: This review followed a five-stage scoping review framework to describe the current knowledge base related to transition from LTCFs to community based private dwellings as the location of the discharge (example: Person's own home or shared private home with a family member, friend, or neighbour). Of the 4221 articles retrieved in the search of 6 databases, 36 articles met the criteria for inclusion in this review.

Results: The majority of studies focussed on an older adult population (aged 65 years or greater), were conducted in the USA, and were limited to small geographic regions. There was a lack of consistency in terminology used to describe both the facilities as well as the transition process. Literature consisted of a broad array of study designs; sample sizes ranged from less than 10 to more than 500,000. Persons who were younger, married, female, received intense therapy, and who expressed a desire to transition to a community setting were more likely to transition out of a LTCF while those who exhibited cognitive impairment were less likely to transition out of a LTCF to the community.

Conclusions: Findings highlight the heterogeneity and paucity of research examining transition of persons from LTCFs to the community. Overall, it remains unclear what best practices support the discharge planning and transition process and whether or not discharge from a LTCF to the community promotes the health, wellbeing, and quality of life of the persons. More research is needed in this area before we can start to confidently answer the research questions.
\end{abstract}

Keywords: Long-term care facilities, Home for the aged, Discharge planning, Older adults, Patient oriented care, Patient centred care

\section{Background}

As populations continue to age across industrialized and emergent nations, the demand for more complex care is increasing. The growing number of frail older adults and vulnerable persons with disabilities necessitate a multidisciplinary response from across the care continuum.

\footnotetext{
* Correspondence: shannon.freeman@unbc.ca

${ }^{1}$ School of Nursing, University of Northern British Columbia, 3333 University

Way, Prince George, BC V2N 4Z9, Canada

Full list of author information is available at the end of the article
}

Symptom presentation is often ambiguous, threats to health multi-factorial, and trajectories of change highly variable with outcomes of care uncertain [1]. Consequently, the pressure on policy makers to respond to the care needs of vulnerable populations is growing $[2,3]$.

Older adults report better quality of life (QOL) when they are able to live and receive support in their preferred location of care [4]. Supporting persons to receive care supports matched to meet their own needs and 
provided in their chosen location may promote the person's sense of control, empowerment, and improve QOL [5]. The majority of persons wish to remain in their own homes and have their needs supported in the community through a combination of formal and informal supports [6]. However, the resources and supports necessary to safely address increased levels of health complexity may not always be available in the community. For these persons, whose needs cannot always be met by available formal and informal supports, long-term care facilities (LTCFs) provide a necessary and appropriate care service.

Various terminologies are used to describe LTCFs including nursing homes, skilled nursing care facilities, personal care homes, residential care facilities, and long-term care homes. This terminology varies both within and across countries. For the purpose of this paper, the term LTCFs will be used and generally refers to care institutions that "serve diverse populations who need access to 24hour nursing care, personal care and other therapeutic and support services" [7] that are not provided through home care programs, in retirement homes, in assisted living facilities, in the persons own home or in a shared private home. Generally, most LTCFs aim to provide a combination of medical, nursing, and social care in a residential care setting.

In Canada, the process to enter a LTCF differs across provincial and regional jurisdictions, but is primarily based on the complexity of clinical health needs of the person and level of dependency in addressing these needs. LTCFs support persons whose needs require more complex care than can be addressed in the community. Although persons who require more intensive levels of care exhibit complex needs and high dependency, they also may prefer to live as normal and unconstrained as possible $[8,9]$. In this way, LTCFs are expected to provide resources to support the residents' autonomy so they may be as active as they can and live their lives the way they want [10]. While the majority of persons exhibiting increased health complexity are older adults, advanced age (e.g. aged over 65 years) is not a requirement for eligibility to LTCFs in Canada.

While the majority of people wish to remain in their homes and be supported to live and die in the community $[6,11,12]$, LTCFs in Canada are increasingly becoming places where older adults reside until death. Yet, not all older adults experience a continuous trajectory of decline in abilities following entry to LTCFs [13, 14]. Following entry to a LTCF some residents experience improvements in personal abilities and increased independence, becoming able to return home or transition to the community [15]. In this case, discharge planning involving multiple stakeholders is warranted [15]. In the United States (US), the duration of stay in a LTCF may be characterized as short and long-term stays [16]. Short-stay residents, who enter due to an acute episode often receive enhanced rehabilitation and care with an expected goal of transition to the community [16], account for more than 1 million discharges from LTCFs to community every year in the US $[15,17]$, a trend that has been reported over multiple decades. In contrast to the large number of discharges from LTCFs reported in the US, transition from LTCFs to the community in Canada is rare. A Canadian study of six provinces by Hirdes, Mitchell, Maxwell, and White found that less than $1 \%$ of LTCF residents transitioned to the community [18].

The definition of 'transition' varies according to disciplinary focus but the widespread definition involves how people respond to change over time [19]. Transition may be defined as "a process of convoluted passage during which people redefine their sense of self and redevelop self-agency in response to disruptive life events" [19]. Transition of care refers to the care a patient receives as they leave one care setting and are moved to another [20]. The American Geriatrics Society describes transitional care as "a set of actions designed to ensure the coordination and continuity of health care as patients transfer between different locations or different levels of care within the same location" [21].

Previous research has focussed upon transitions from hospital to other care settings including LTCFs [22, 23] and examined transitions from LTCFs to hospital or emergency departments [24]. However, to the knowledge of these authors, no scoping review has been conducted to critically examine the existing evidence about transitions from LTCFs to the community. Therefore, this article aimed to review the published scientific research studies about transition from LTCFs to the community to examine what is known about the discharge process and its associated factors by answering three main questions:

1. What are the characteristics of the residents who have been discharged from LTCFs to the community?

2. What are the associated factors surrounding resident discharge from LTCFs to the community?

3. What are outcomes experienced by residents post-discharge?

\section{Methods}

The five-stage scoping review framework outlined by Arksey and O'Malley [25] was used to describe the current knowledge base related to transition from LTCFs to the community. These stages included: (1) identification of the research question, (2) identification of relevant studies, (3) study selection, (4) charting the data, and (5) collating, summarizing, and reporting the results. This scoping review methodology was selected for its capacity 
to "map relevant literature in the field" [25]. It also allowed researchers to draw conclusions on the overall state of research activity on a topic and suggest future directions for research [25]. Although scoping reviews do not address the quality of included sources, this method was appropriate for this emerging field of study and provided a rigorous framework to carry out a review systematically.

\section{Search strategy (identification of relevant studies)}

Six databases were used to search for relevant literature on the transition from LTCFs to the community: SCOPUS, PubMed, CINAHL EBSCO, PsychINFO EBSCO, Embase OVIDSP and Web of Science ISI. The literature search was performed with the assistance of a research librarian at the University of Northern British Columbia in Canada. Articles published from January 1, 2000 to December 1, 2015 were selected to be both inclusive and relevant.

Search strategies were created for individual databases. These strategies involved various combinations of keywords and subject headings (when available). These terms included: facility, residential home or care, nursing home, home for the aged, long term care, assisted living, convalescence, and home care, private dwelling or home, independent living, living alone, and discharge, transfer, exit, move or transition. Searches were limited to English language articles only.

\section{Study selection}

Inclusion criteria specified that included articles must 1) focus on resident transition from a LTCF; 2) include a community based private dwelling as the location of the discharge (e.g. Own home, shared private home with family member, friend, or neighbour); and 3) include persons over the age of 18 . Articles exclusively studying persons discharged from acute care, hospital, or noninstitutional setting were excluded from the review. Additionally, articles were excluded if the population in the study was discharged exclusively to communal or congregate setting (e.g. group home). Due to the changing nature of LTCFs both in terms of populations and regulatory policies and procedures, articles published prior to January 2000 were also excluded.

After screening titles and abstracts for relevancy, two authors reviewed full-text articles independently. If a discrepancy occurred amongst the reviewers, a third reviewer was consulted to make an inclusion or exclusion decision through collaboration and consultation. Interrater reliability noted $98.8 \%$ agreement between the two authors. A detailed article search chart outlining inclusion and exclusion data can be found in Fig. 1. From the original 4221 non-duplicate articles selected for review,

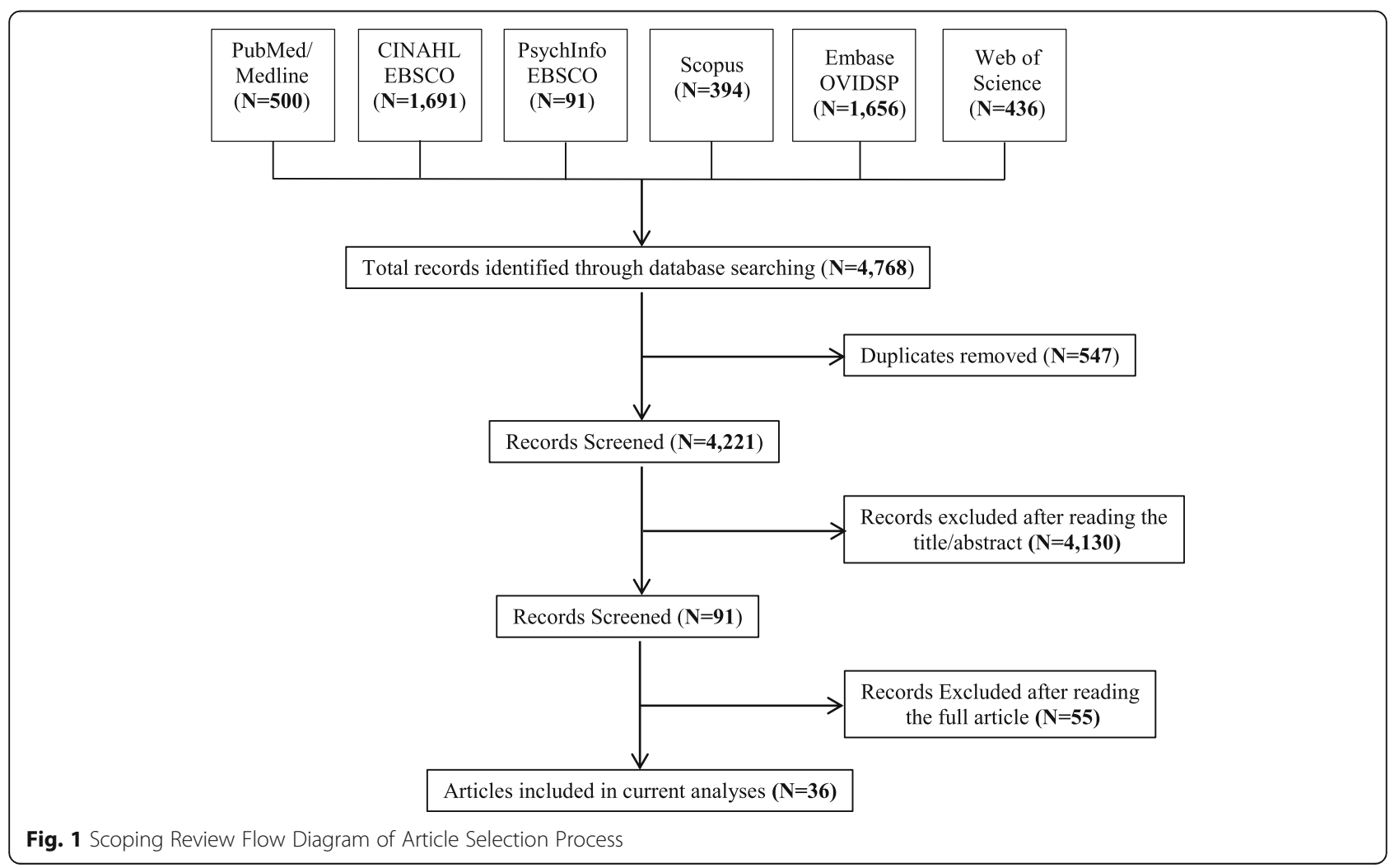


36 articles met criteria for inclusion in this scoping review. Microsoft Excel was used to categorize, extract and organize the data. Thematic and descriptive numerical analyses were conducted on all extracted data.

\section{Results}

A summary of characteristic from the 36 articles can be found in Table 1. Study objectives and post-discharge outcomes are described in Table 2 while the purpose and main findings of all articles are presented in Table 3 . With the exception of seven articles [26-32], the majority of articles focused on older adults (29/36), specifically those aged 65 or greater [33-47]. A few articles focused on specialized populations that shared a similar characteristic such as persons with an intellectual disability $[30,32,48]$ or persons who had a stroke $[26,46]$. One article focused on persons who had a common experience of a motor vehicle accident [33]. The majority of articles (30/36) included both males and females [26, 28, 30-37, 39-59]. The main focus for most articles $(21 / 36)$ was on resident profiles [26, 28, 32, 33, 35, 36, $40-47,51,53-57,60]$. The study designs employed predominantly quantitative techniques $[26,28-30,32-38$, $40,42-57,60]$. Research in this area represents a new and emerging field where over half of the included articles $(22 / 36)$ were published in the last 5 years $[26$, 28, 29, 31, 35-38, 41-45, 47-50, 52, 54-56, 60] (Fig. 2).
Study sample sizes had a large range from less than 20 participants [31] to more than 500,000 participants in the largest sample [37]. Almost all studies were conducted in the US $[27-30,33-39,41,42,44,45,47-55$, $57-61]$. Non-US research in this area is scarce [26, 31, $32,40,43,46,56]$ and only one article used data gathered from more than one country [32, 46]. Authors' background and type of institution varied across studies. Single academic institutional authorship was most prevalent $(21 / 36)[26-28,30-34,36,41,44,48,51-$ $55,57,58,60,61]$, of which five also included author partners from community locations such as hospitals and LTCFs $[33,34,51,56,60]$ and five included research institutes, centres for aging, and non-profit partners [28, 30, 31, 36, 52]. Just over one-third of articles $(14 / 36)$ were inter-institutional collaboration $[29,35,37,38,40,42,43,45-47,50,51,56,59]$ of which six included additional community and research institutional partners $[29,37,46,49,50,56]$ and four were multi-national collaborations [35, 40, $43,46]$.

\section{Terminology}

Terminology used varied across studies. When describing the process of leaving the LTCF and returning to the community, terminology to describe the transition

Table 1 Description of studies characteristics background $(N=36)$

\begin{tabular}{|c|c|c|c|}
\hline Study Characteristic & Number of Studies & Study Characteristic & Number of Studies \\
\hline Study Population: & & Study Design: & \\
\hline - Older adults & 29 & - Quantitative & 30 \\
\hline$\cdot \geq 65$ years as inclusion criteria & 15 & - Longitudinal & 17 \\
\hline - Average age $\geq 65$ years & 24 & - Cross-sectional & 5 \\
\hline - Person with intellectual disabilities & 3 & - Quasi-experimental controlled trial & 1 \\
\hline - Persons with functional limitations & 1 & - Randomized control study & 1 \\
\hline - Persons who had stroke & 2 & - Prospective cohort & 3 \\
\hline - Persons with motor vehicle crash trauma & 1 & - Retrospective cohort & 2 \\
\hline - Persons with specified conditions & 1 & - Case Control & 1 \\
\hline Data Type: & & - Mixed methods & 4 \\
\hline - Primary & 11 & - Qualitative & 2 \\
\hline - Secondary & 19 & Sample Size: & \\
\hline - Both primary and secondary & 6 & $\cdot<500$ & 16 \\
\hline Study Focus: & & • 500-10,000 & 12 \\
\hline - Persons only & 21 & $\cdot>10,000$ & 8 \\
\hline - Persons and one or more stakeholder(s) & 13 & Country of Study Origin & \\
\hline - Institution and policy documents & 4 & - United States of America & 30 \\
\hline Distribution By Sex: & & - Australia & 2 \\
\hline - Mixed sex-sample & 30 & - Finland & 1 \\
\hline \multirow[t]{3}{*}{ - Unspecified } & 6 & - Germany & 1 \\
\hline & & • Lithuania & 1 \\
\hline & & - United States of America and Canada & 1 \\
\hline
\end{tabular}




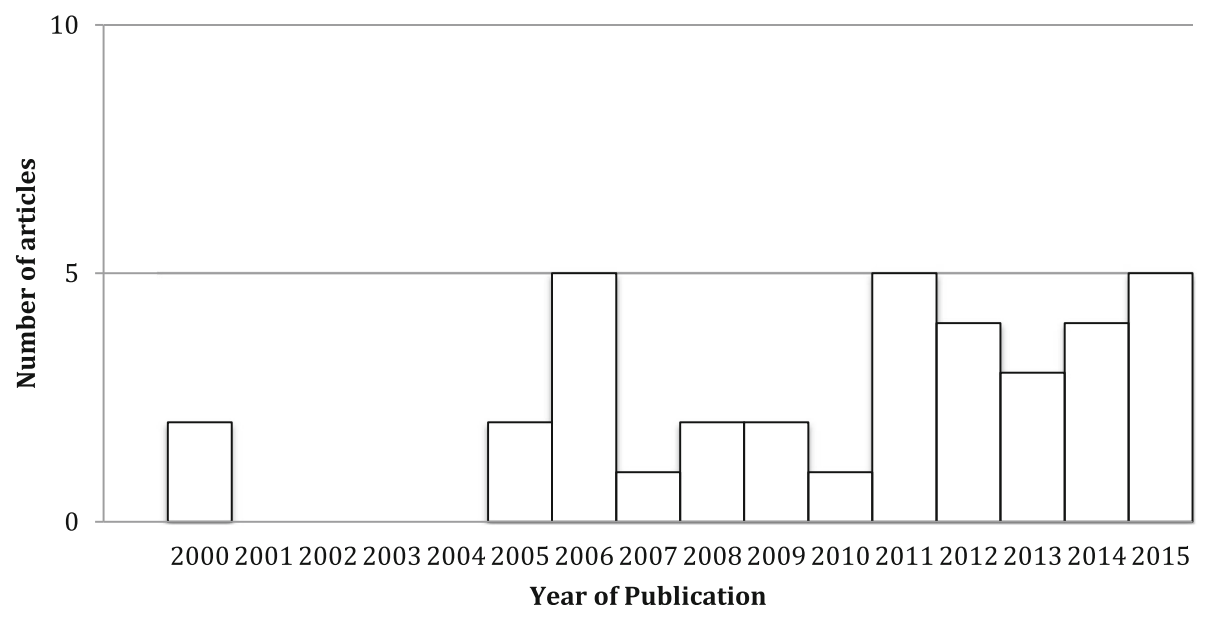

Fig. 2 Articles Included by Year of Publication (2000-2015), N = 36

included: discharge $[26,27,31-33,37,39,41-43,45-47$, 53-57, 59-61], community discharge [36, 38, 40, 44, 49-51], community transition [36, 38, 42, 49, 50], transition $[27,28,30,31,34,35,41-43,47,48,52,60]$, nursing facility transition [54], nursing home transition [29, $39,49,57]$, return to the community $[28,37,38,40]$, return to community [41], deinstitutionalizing [56], transitioning [27, 28, 58], emancipation [29] and relocation [32].

Study locations also varied. LTCFs were referred to as long-term care facilities [43], nursing homes [26-29, 33-36, 38, 39, 41, 42, 45-47, 49-52, 54-59, 61], nursing facility $[27,36,41,44,48-52,54,58]$, skilled nursing facilities $[37,45,46,53,60,61]$, long-term institutional care $[40,50]$, long-term care welfare facilities [56], longterm care medical facility [56], long stay placement [44], residential facility [30], aged care facility [31] and longterm institutions [32]. Only a few studies provided information about the size of the institution, such as the number of beds, average occupancy rates or physical dimension of the facility [30, 38, 45, 48, 49, 61].

\section{Theoretical framework or approach}

Explicit mention of the theoretical perspective use to guide the research in this field was rare; only three articles mentioned a theoretical framework in their study or analysis. The theoretical frameworks mentioned included: an ecological model of health behaviour to investigate characteristics of facilities that influence transition to the community [38]; and Anderson's model for health care $[62,63]$ to select and classify variables that might influence the risk of LTCF readmissions [39, 42]. Two others specified conceptual approaches in their studies: conceptual mapping technology developed by Trochim [64] was used to conceptualize key elements or theoretical domains of an intervention plan [27]; and Grounded Theory [65] to analyse qualitative data [31].

\section{Planning for discharge from LTCFs}

Approximately one-third of the articles (14/36) described a discharge initiative. Some studies used programs $[28,39,52-54,57,61]$, such as The Ohio Diversion and Transition Program [52] or New Jersey's Nursing Home Transition Program [39]. Some articles described a discharge initiative organized as a project (i.e. New York State Department of Health's "Project Home" [41]), a plan (i.e. post discharge home care plans [56]) or study interventions (i.e. cluster centre and community living compared to residential institutions [32]) $[27,29,30,32,41,44,56]$. Discharge initiatives were limited to local and regional action with the exception of one, which targeted a collection of nursing facility transition programs across multiple US states [54].

The length of stay residents experienced prior to their transition out of LTCF's differed across studies. Some articles focussed on transition programs for residents who had resided in the facility for a short period of time (approximately 90 days) [44-46, 48, 49, 51, 57, 61]. Other studies focussed exclusively on residents with longer stays (generally greater than 100 days) [30, 32, 40, 43, $47,54,56,58]$. Several studies mentioned very long stays $[30,32,40,43,56]$, with average lengths of stay greater than 2 years. Some articles included both short and long stays in LTCFs [33, 36, 38, 39, 50, 55].

\section{Transition to community location}

Studies reported a variety of locations to which residents transitioned. Some focused directly on transition to community $[27-31,34,35,37-43,46,47,49,50,53-58$, $60,61]$. Of these, six articles specified that the transition to the community was accompanied by community- 
based support services [27, 30, 31, 35, 47, 49] and only three articles provided more information specifying the type of community location [35, 42, 56]. Interestingly, some studies examined residents as they transitioned across the care continuum starting from the hospital and traced patient transitions to LTCFs and then followed the same patient's as they transitioned to the community [33, 45, 59]. In contrast, other studies included discharge from LTCFs to multiple locations of care, including the community (private residence with home health, private residence without home health) as well as other locations including group homes, assisted living, other nursing home and an acute-care hospital $[36,44,50,52]$. Finally, one article did not focus on the discharge, but on all transitions among different locations of care [48]. This study included the transitions of residents among places including home/community, home without formal services, home with formal services, nursing facility, skilled nursing facility and hospital.

Five studies emphasized the importance of personcentred care to tailor the transition process to meet the individual needs of the resident [27-29, 41, 43]. Findings from the "Project Home" intervention emphasized that a person-centered care approach that "includes responsiveness to individual needs, the flexibility to match those needs with creative solutions, and the coordination of service providers, is a feasible and effective way to maximize positive outcomes for older people who want to live at home." [41]. Furthermore, person-centered care planning activities may not only inform tailoring of care plans but may also serve as a foundation for effective care team collaboration during the transition between the LTCF and community care providers [43].

\section{Objectives and outcomes}

Details describing study objectives and post-discharge outcomes are described in Table 2. Less than half of the articles presented post-discharge outcomes [26, 28, 31$33,36,39,45,47-49,52,53,55,61]$, of which few were described in depth. Transition outcomes examined included length of time residents were able to remain in the community post-transition, readmission to a nursing facility, hospitalization and mortality.

\section{Characteristics of residents who had transitioned out of LTCFs}

Considering the individual determinants of health services utilization [63], characteristics of the persons residing in LTCFs potentially eligible for discharge should be considered key to the transition process. The needs identified by articles included in this review were primarily individual determinants. Residents residing in LTCFs were most likely to transition out of LTCFs if they were younger [58], married [36, 51], female [36, 42], had Medicare coverage [51], experienced daily pain [51], participated in or received intense therapy [51], were responsible for their own decisions [36] and preferred return to the community $[36,39,50]$. Residents who had recently had fractures were also more likely to return to the community $[44,45]$. In contrast, residents were less likely to be discharged to the community if they had cancer [36] or were cognitively impaired [36].

Other facilitators important to transition included: independence of the persons in cognitive and functional abilities [33, 39, 43, 50, 56, 58], medical stability [39] and fitting a community discharge profile [50]. Furthermore, persons were more likely to transition out of a LTCT if they received independent living training or community skills training [27, 36], caregiver support [27, 36, 50], medication management [60] and community supports were made available to assist the person in activities of daily living $[43,49]$.

\section{Stakeholders involved in the transition}

Discussion of the roles various stakeholders played during the transition decision making and care planning process was lacking. Less than one third of articles identified which formal care providers were involved. Of the articles that described the involved stakeholders, a wide variety of formal care providers were mentioned including: case managers, discharge planners, counsellors, residents, proxies, families, staff members and researchers. Interestingly, only one study described involvement of a care team involving stakeholders across the care continuum representing the LTCF, the community, and the person to be transitioned [57], whereas the other articles described involvement of stakeholders from only one or two locations of care.

Half of the articles (20/36) clearly mentioned informal caregivers $[26,27,31,33,39-43,45,47-49,51,52,56-$ 59,61 , yet only two of them defined the role of the caregiver as "providing the most assistance with care or arranging care in the 6 weeks after the hospital discharge" [59] and "help family members or friends get what they need to live at home or in another community-based setting" and "participate in discharge planning" [27].

\section{Factors associated with the transition journey}

A wide range of key risk and protective factors were identified at different times, from the time of "pre-discharge planning" (considering characteristics which would enable or deter the identification of potential for discharge to the community and/or influence the process to develop the discharge plan), through the "discharge process" (the transition of leaving the LTCF and returning to the community), and finally examining outcomes "post-discharge" (factors affecting the degree of discharge success and sustainability). The factors 


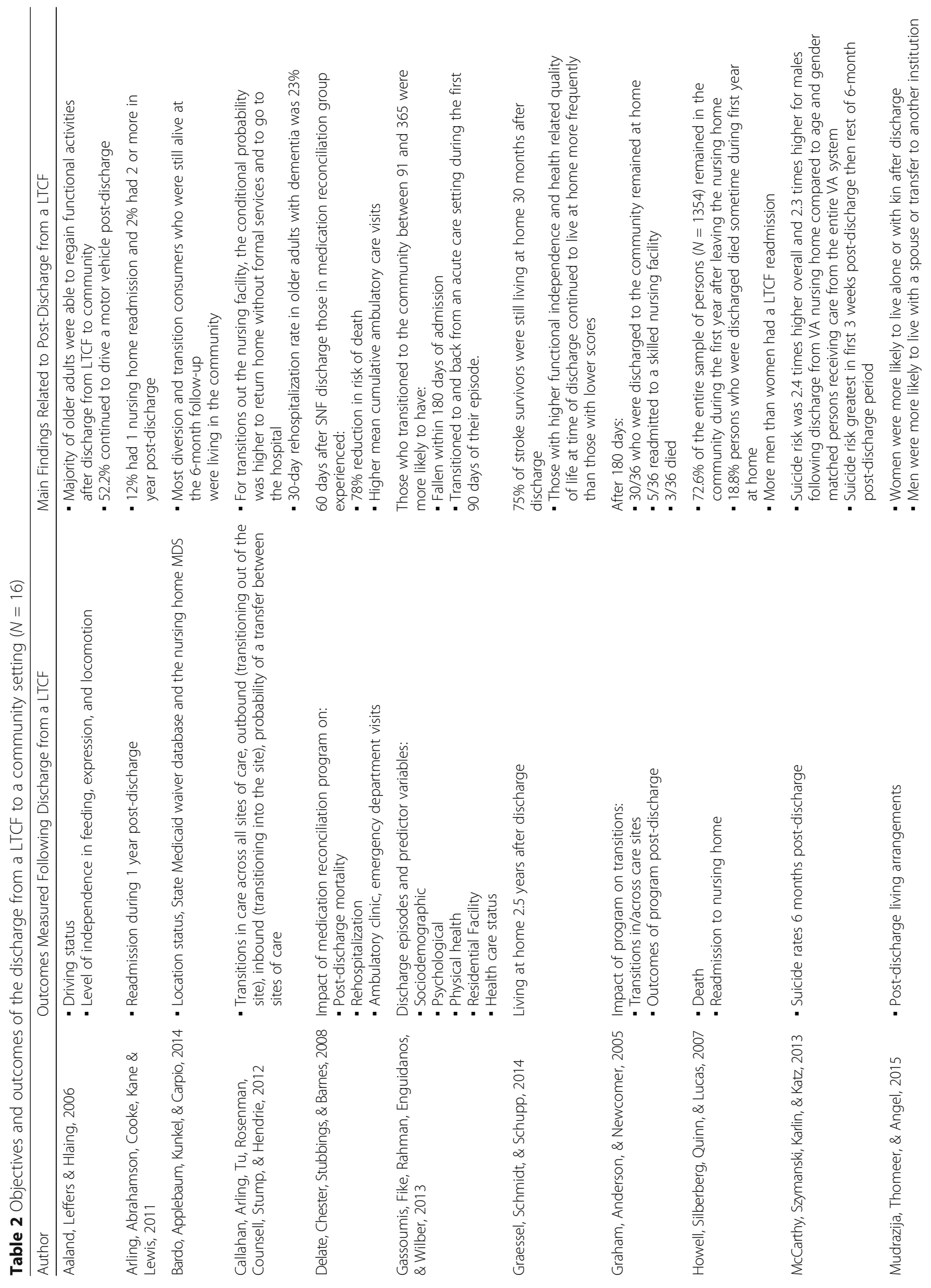




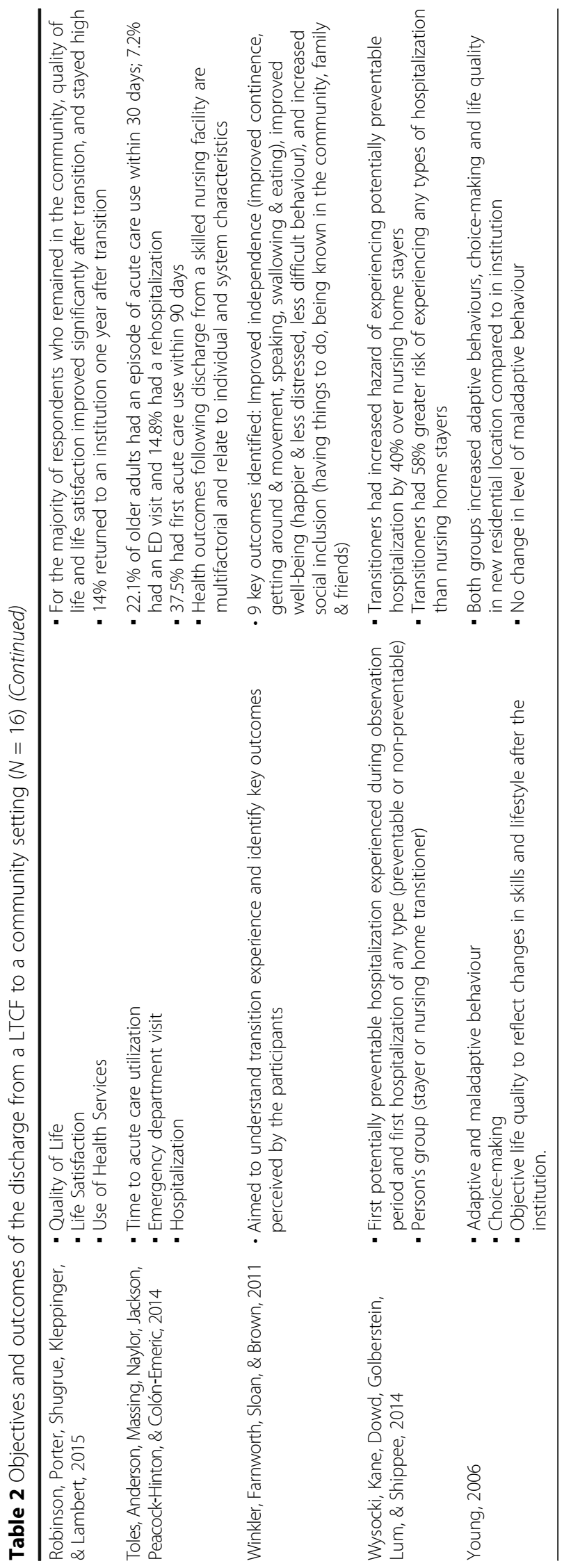


identified across these three phases in the discharge journey are described by individual, institutional, and community levels of needs and characteristics below.

\section{Factors associated with 'pre-discharge planning'}

In the 'pre-discharge planning' phase, independent living training or community skills training $[27,36]$, caregiver support [27] and medication management [60] emerged as important individual level needs. At the institutional level, case management support, transitional assistance, administrative procedures, assessment, discharge planning processes and nursing facility collaboration were identified as necessary characteristics to support a plan for a discharge process. Facility characteristics including size, occupancy, ownership, average length of stay, proportion of Medicare and Medicaid residents, and the proportion of residents admitted from acute care facilities [38] were all factors, which influenced the likelihood of resident discharge to community. At the community level, education, advocacy, housing, consumer centred planning policy and funding opportunities [27] were identified as critical to inform whether discharge was feasible.

\section{Factors associated with the transition process}

To support the transition process, individual need characteristics identified as facilitators of discharge included independence of the persons in cognitive and functional abilities [33, 39, 43, 50, 56, 58], the person's preference for discharge to the community [39, 50], medical stability [39] and fitting a community discharge profile [50]. Only one article [31] identified institutional level characteristics for transition process which included support provided by LTCF staff, consistency of LTCF care, and staff respect and dignity for the person. Community characteristics aiding the transition process included support for community discharge by a family member or other person close to the person $[36,50]$ and availability of community supports to assist persons in management of activities of daily living [43, 49].

Factors affecting the degree of transition success or outcomes post-discharge are limited. Receiving care in a LTCF with more licensed practical nurse hours per resident day [45], and longer duration of skilled nursing facility treatment [45] resulted in lower risk of acute care use post-discharge. Other institutional characteristics, which positively influenced post-discharge outcomes, included residing in LTCF with high percentage of admissions receiving therapy [51] and higher rehabilitation therapy intensity [46], as well as LTCFs with high investment in nursing staff [49] and high volume skilled nursing facilities [37].

\section{Recommendations for further study}

Most articles highlighted existing inconsistences in the knowledge base and areas where further research is warranted. Recommendations for better understanding of the complexity of the discharge process, included further evidence summarizing factors and barriers that can influence the discharge such as: environment circumstances, proxy relationships, personal preferences, family and informal caregivers, nursing home staff and other health-care providers $[27,28,35,37,38,45,48,51,52$, $58,59]$. Moreover, further research was suggested to expand understanding of outcomes following the discharge $[30,31,33,42,48,51,55]$; and evaluation or improvement of existing discharging programs or initiatives [34, 42, 44, 50, 51]. Recommendations specific to study methods and protocols included more rigorous study methodology (increased sample size, replication across geographic regions) $[27,36,45,51,53]$ and the requirement for expansion of study results [32, 39, 45, 60]. There was also a need to better understand the influence of quality and intensity of health care provided during the pre-discharge planning process $[46,51,56]$.

\section{Discussion}

Study findings highlight the heterogeneity and paucity of research examining transition of persons from LTCFs to the community, especially when considering the international context. Overall, the generalizability of findings in this scoping review remains greatly hindered as most were conducted in small geographic areas across the US and were led by single academic institutions. The majority of studies focussed on older adult populations with a patchwork of evidence on special populations with a shared health condition/diagnosis (i.e. stroke or acquired brain injury) or shared client experience (i.e. traumatic life event). Overall, it remains unclear what mix of multidisciplinary team members and institutional factors best support discharge planning and transition process. And finally, due to a lack of studies measuring post-discharge outcomes, it remains unclear from the current body of evidence whether discharge from a LTCF to the community promotes the health, wellbeing and quality of life of those who transition out of LTCFs and whether these transitions are cost-effective for the health care system. More research is needed in this area before we can start to confidently answer the research questions.

No gold standard emerged for the best time to identify and engage persons who may be eligible for transition out of a LTCF to the community in discharge planning activities and processes. Variation in the association between length of stay in a LTCF and potential for discharged was observed. For example, Arling [50] indicated that $85 \%$ of discharges occurred within the first 30 days of admission while Gassoumis [36] noted 
that the percentage of persons discharged increased to $90 \%$ within the first 90 days of entry into LTCF [36]. Interestingly, Gassoumis [36] also noted that a resident's preference to discharge showed no effect on discharge to community after a 90 day or greater length of stay.

Considering the individual determinants of health services utilization [63], characteristics of the persons residing in LTCFs potentially eligible for discharge should be considered key to the discharge process. The needs identified in this review were primarily individual determinants. Residents residing in LTCFs were most likely to transition out of facilities if they were younger [58], married [36, 51], female [36, 42], had Medicare coverage [51], experienced daily pain [51], participated in or received intense therapy [51], were responsible for their own decisions [36] and preferred return to the community $[36,39,50]$. While demographic characteristics such as gender and age may be associated with the discharge process they were not recognized consistently as the strongest factors predicting discharge to the community. Other important facilitators of discharge included independence of the persons in cognitive and functional abilities [33, 39, 43, 50, 56, 58], medical stability [39], and fitting a community discharge profile [50]. Furthermore, persons were more likely to transition out of a LTCT if they received independent living training or community skills training [27, 36], caregiver support $[27,36,50]$, medication management [60] and community supports were made available to assist persons in management of activities of daily living [43, 49].

In contrast to Poole who noted that "the need for person or 'consumer-centered' planning is widely cited in the transition literature" [27], findings in the current study suggest it may be less commonly discussed. Less than $15 \%$ of articles (5/36 articles) in the current study discussed person-centered care. Although all of the number of studies were few, those that did discuss patient centered care emphasized the crucial role that person centered care planning plays to ensure the needs and preferences of the resident are heard and respected, Case managers and discharge planners play an important role to support patient centred care, provide education to the person and caregivers, and promote communication among multidisciplinary teams during transitions across the care continuum [66, 67]. Findings from the Project Home intervention noted that when a flexible organizational structure exists that empowers its case managers to advocate for client goals and preferences, then a person centered approach to care may be realized [41]. To ensure the person transitioning out of the LTCF is able to improve their health and QOL, it is important that the goals, values, and preferences of the resident be considered and incorporated throughout the discharge process. When the person residing in a LTCF, who is identified as a candidate for transition back to the community, is not the centre of the person-centred plan for care, the discharge care plan may be unsuccessful [68]. Considering this, further research is needed to examine best practices in patient centred care planning practice during the transition (discharge) process from planning to intervention and evaluation for residents transitioning from LTCFs to the community.

This scoping review identified a lack of focus on positive post-discharge outcomes such as measuring the impact of discharge on the resident and their informal caregivers' health and QOL. Only one study [28] measured QOL and life satisfaction as post-discharge outcomes. Robinson et al. [28] found that QOL and life satisfaction improved for the majority of respondents who transitioned from an institution to the community. An interesting post-discharge outcome related to QOL was suicide rates post-discharge. One study revealed that suicide risk was significantly elevated following discharge from a Veteran Affairs (VA) nursing home compared to matched persons receiving care from the VA system [55]. This study indicated that suicide risk was greatest in the first 3 weeks post discharge [55]. While this study was limited to a population of older veterans it is an important finding as suicide can be indicative of life dissatisfaction [69] and warrants further research.

Other studies focussed on measureable available outcomes such as death, rehospitalization, or readmission without describing in depth the role that the discharge process had in relation to the outcome. Meaning, if the person died, the research did not describe in detail how the transition related to that death. It would be beneficial for future research to investigate whether outcomes which occurred post-discharge would not have occurred or have been preventable had the person not transitioned out of the LTCF. LTCF readmissions and their predictors, important measures at post-discharge, are used to plan interventions and allocate resources [39]; however it is also essential to look deeply at both positive and negative benefits that transition to the community may evoke. Gains obtained with transition to the community may be related to independence, well-being and social inclusion [31]. However, more research examining what occurs after discharge is a topic where more studies are needed $[33,48]$.

To determine the degree to which the post-discharge goal to improve the person's health, wellbeing, and QOL 
was attained, outcome measurements should include both objective and subjective measures. While the majority of studies used individual level data and described a focus on the person, there was a lack of reporting of person-centred goals, values and preferences in relation to discharge and post-discharge outcomes. Instead, articles in the current review focused on measurable outcomes such as death, rehospitalization or readmission without describing in depth the person's perspectives on improvements in their health, life satisfaction or QOL. It remains unclear from the current evidence available whether person-centred goals can be obtained post-discharge. Further research in this area should focus on measuring whether persons were able to receive postdischarge care supports in their new location, which were matched to their person-specific need. Moreover further research should examine whether the transition was successful to promote the person's sense of control, empowerment, and improve their QOL as had been noted by Fry [5].

Finally, the needs to transition related to discharge planning for residents should include the needs and preference of informal and formal care supports that will be caring for persons in the community. Of the articles included in this review, fewer than half of the articles described the perspectives of stakeholder's involvement in the transition. There remains a gap in understanding regarding the availability of and eligibility for community based care services and supports. These articles highlight a gap in our understanding of post-discharge outcomes and whether or not current transition programs are successful from the perspective of the person of focus and their circle of care.

Due to the emerging nature of research in this field, a systematic review is not yet warranted. Among the reviewed articles there was a lack of generalizability due to variation regarding the location as most articles were limited local studies and were conducted in the US. The US health system organization is unique, well-marked by Medicare and Medicaid programs for older adults and low-income people [70], making the findings obtained very specific and concentrated, and their use difficult for the international scientific community. It is unclear whether study findings would be applicable in other health care systems such as the Canadian publically funded system [71], Switzerland's universally mandated private insurance system [71] or a two-tier system such as Japan's [71]. Lack of generalizability of research findings necessitate further research and replication of studies [45] in this area to better understand processes and outcomes regarding discharge from LTCFs.

Articles reviewed in this study presented many recommendations for future research acknowledging inconsistences in the knowledge base and highlight areas where more research is needed. Gaps identified in currently available research warrant further research to expand understanding of the factors and barriers, which influence discharge in order to inform policy regarding transitions in care to the community. Despite an increase in the literature on this topic in recent years, there is still a need for better understanding of the complexity of the discharge process and the factors and barriers, which can influence discharge. This includes the need for more research on post-discharge outcomes when transitioning from a LTCF back to the community.

CIHR implemented Canada's Strategy for Patient-Oriented Research (SPOR) to address Canada's struggles with turning influential research into high-quality and cost effective care [72]. Moving forward there is a clear need for more patient centred research in regards to transitions from LTCFs to the community and emphasis placed on measuring whether the person in fact experienced improve health, wellbeing, and QOL. While there is an understanding of measurable post-discharge outcomes such as death, rehospitalization and readmission there is a need to better understand patients experiences and whether or not these discharge programs are successful from the point of the persons of focus and the perspectives of members of their circle of care including their informal caregiver(s). In addition, future research should investigate whether post-discharge outcomes would have/have not occurred, been prevented, or delayed had the person not transitioned out of the LTCF.

\section{Conclusion}

This scoping review presents the scientific scenery of discharge out of LTCFs to community-based locations such as private homes, shared residences, or independent care. Most studies included older adult populations, were based in the USA, and focussed on understanding residents' perspectives. Gaps remain in the understanding of post-discharge outcomes such as effects on the person's health, wellbeing and quality of life. Little is known about whether or not the discharge programs are successful from the person's perspective and from the views of members of their circle of care. To create best practices in this area, future research needs to expand understanding of the barriers and facilitators of resident transitions and provide more detailed description of subjective and objective post-discharge outcomes. Additionally, there is need for replication of study findings and to expand generalizability of findings beyond small geographic regions in the USA. With such evidence, the option to transition from LTCFs to the community can be further developed. 
Freeman et al. BMC Health Services Research (2017) 17:689

Page 12 of 19

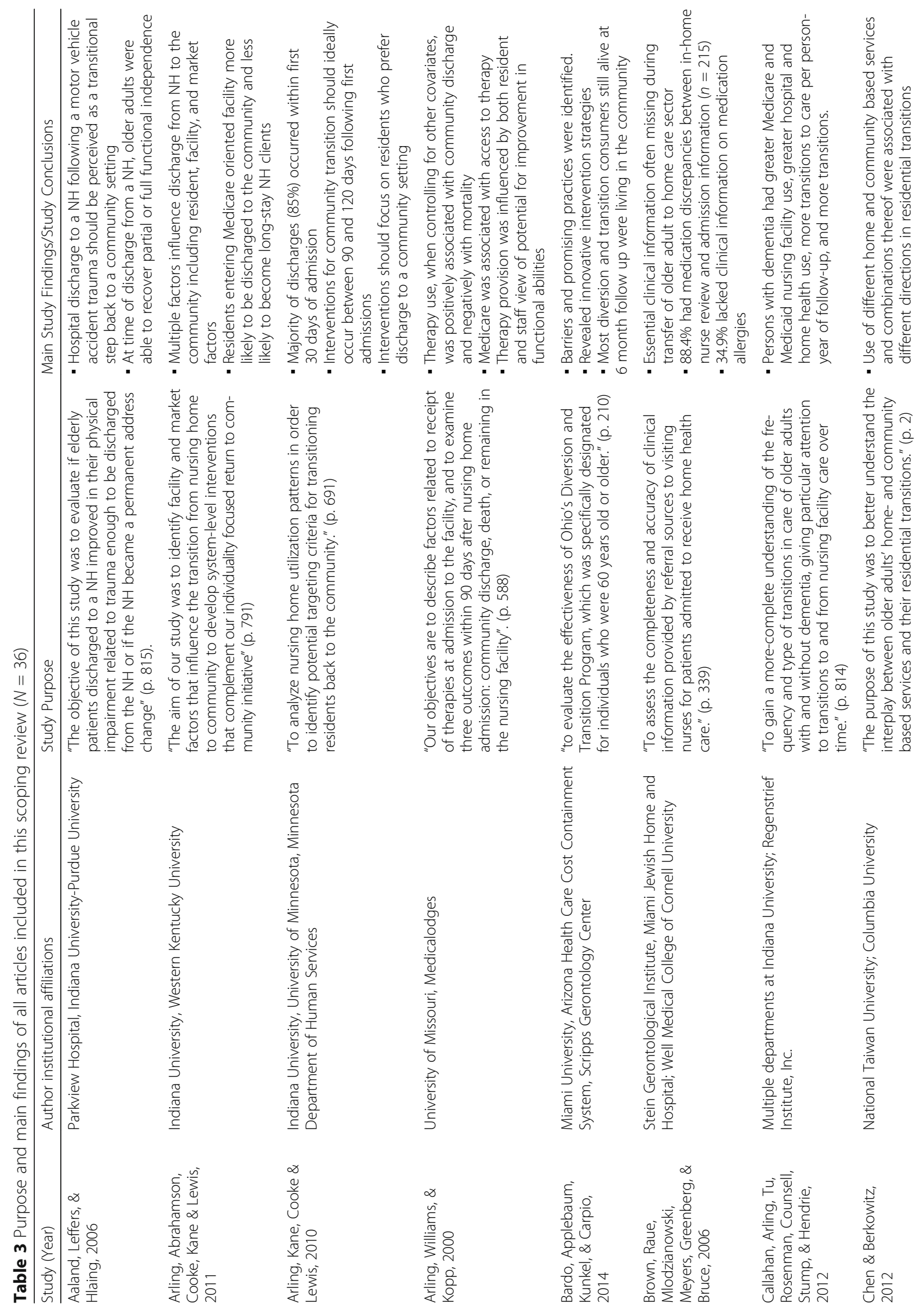




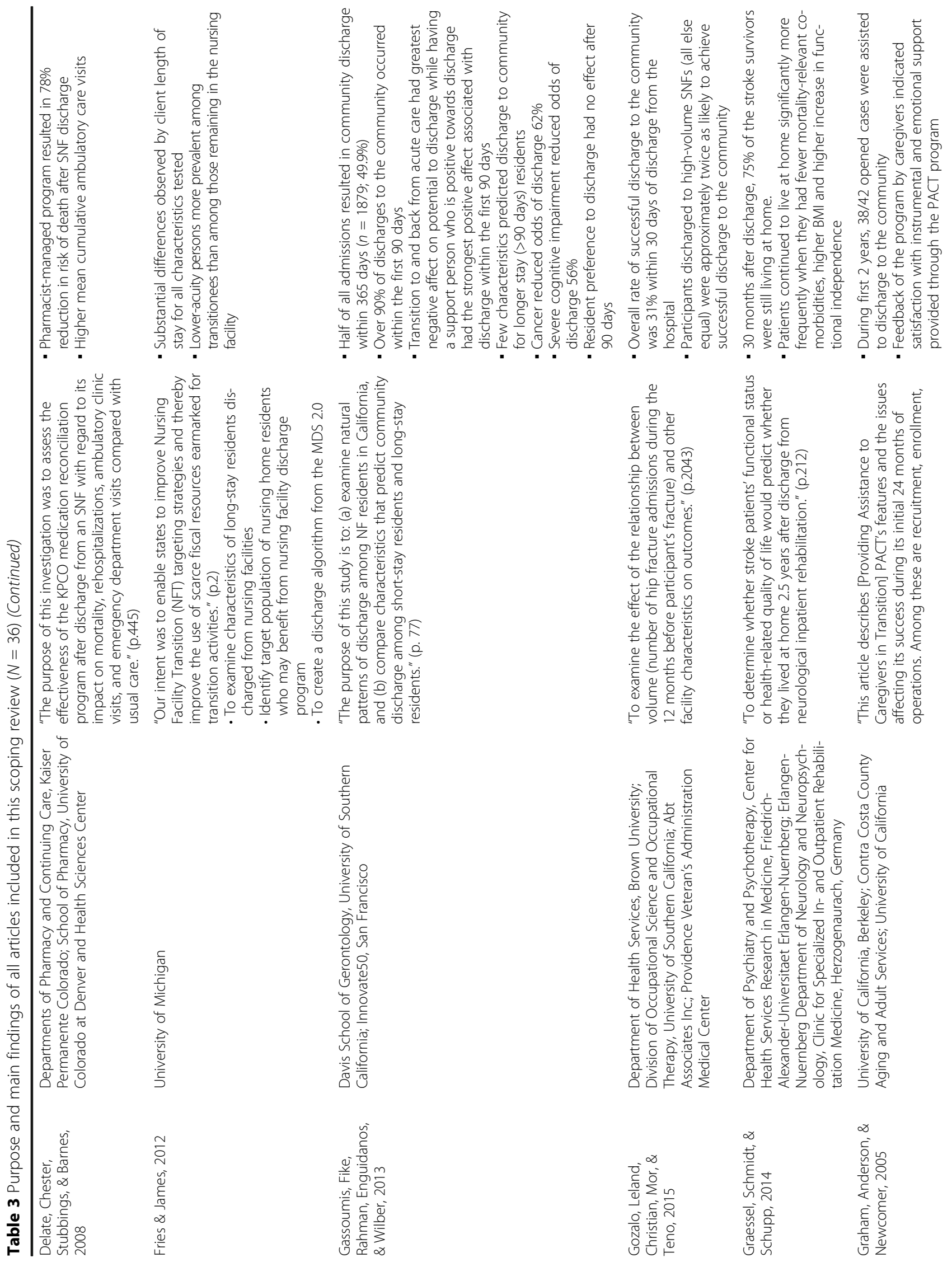




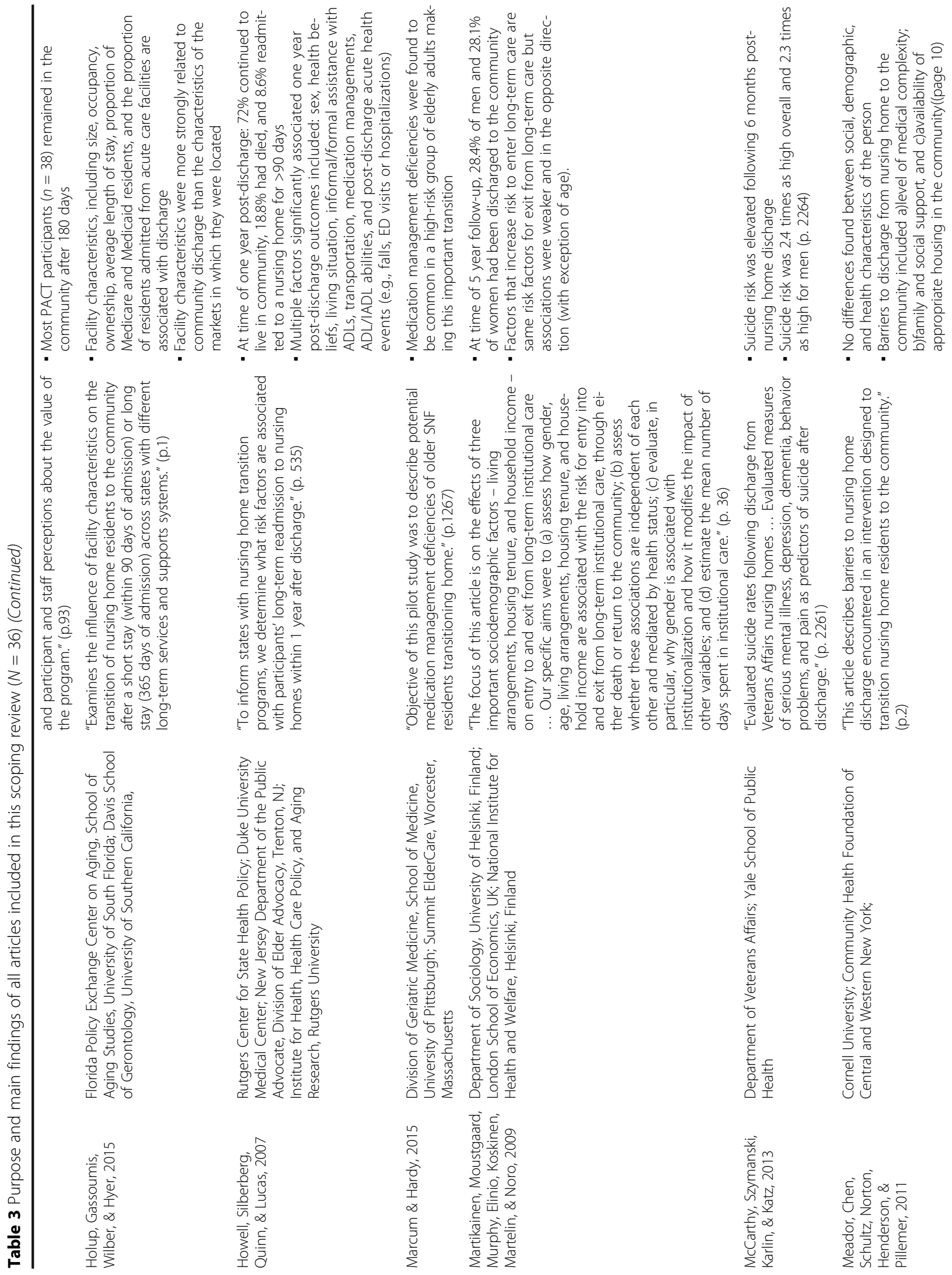




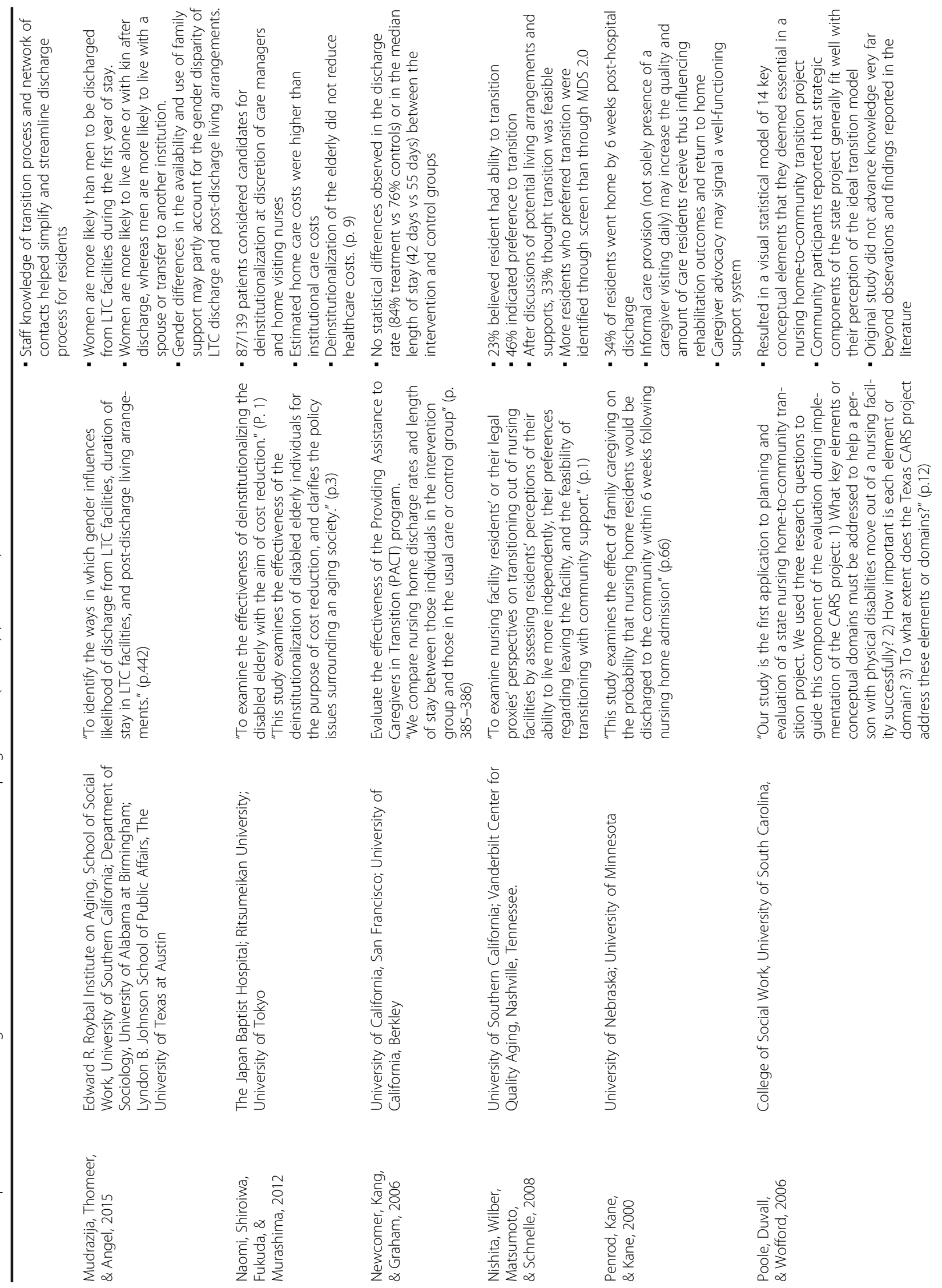




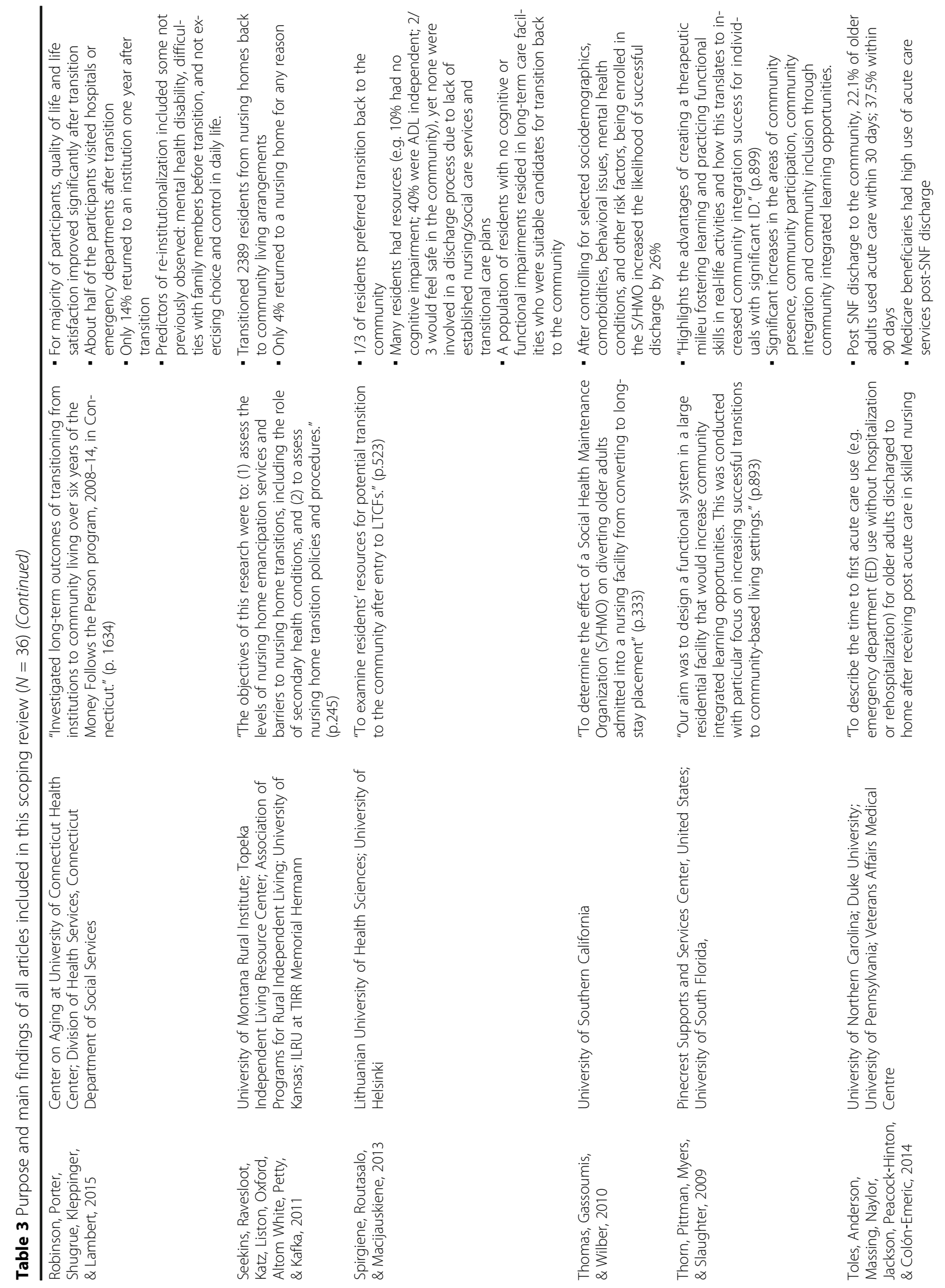




\section{Abbreviations}

LTCF: Long term care facility; QOL: Quality of life; SNF: Skilled nursing facility; VA: Veteran Affairs

\section{Acknowledgements}

The authors wish to acknowledge the time and efforts of Jordan Jackson, Sam Rosario, Mercedes Ouellet, and Grace Gu for their contributions on this project. SF also wishes to thank Tom MacLeod and the Northern Health Authority for the opportunity to build this collaborative research partnership.

\section{Funding}

The authors wish to acknowledge financial support was received from the Northern Health Authority RC11-2508. SF received Postdoctoral Fellowship funding from the Northern Health Authority (2014-2015) and the Canadian Institute for Health Research (2015).

\section{Availability of data and materials}

Not applicable

\section{Authors' contributions}

SF oversaw and coordinated all aspects of this study. SF, KB, LS, and MM conceived and designed the study. SF, KB, LS and TF designed the search strategy and oversaw data extraction, selection, and synthesis. FCB and EK were involved in data extraction, selection, and synthesis. SF, KB, LS, and EK actively engaged in all aspects interpretation of the findings and drafted the manuscript. FCB, TF, SP, BX, and MM critically revised drafts of the manuscript and provided valuable feedback. All authors made valuable contributions to the development and refinement of this manuscript and its intellectual content. All authors read and provided approval of the completed manuscript.

\section{Ethics approval and consent to participate}

Not applicable

\section{Consent for publication}

Not applicable

\section{Competing interests}

The authors declare that they have no competing interests.

\section{Publisher's Note}

Springer Nature remains neutral with regard to jurisdictional claims in published maps and institutional affiliations.

\section{Author details}

${ }^{1}$ School of Nursing, University of Northern British Columbia, 3333 University Way, Prince George, BC V2N 4Z9, Canada. 'Faculty of Health Sciences, Health and Rehabilitation Sciences, Western University, 1151 Richmond St, London, ON N6A 3K7, Canada. ${ }^{3}$ Department of Nursing and Care, Lithuanian University of Health Sciences, Mickevičiaus 9, -44307 Kaunas, LT, Lithuania. ${ }^{4}$ School of Health Sciences, University of Northern British Columbia, 3333 University Way, Prince George, BC V2N 4Z9, Canada. ${ }^{5}$ School of Public Health, University of Sao Paulo, Dr. Arnaldo Street 715, Sao Paulo, SP 01246-904, Brazil. ${ }^{6}$ Northern Medical Program, University of Northern British Columbia, 3333 University Way, Prince George, BC V2N 4Z9, Canada. 'School of Nursing, Jilin University, 965 XinJiang Street, ChangChun, JiLin 130012, China. ${ }^{8}$ Department of Quality, Planning and Information, Northern Health, 543 Front Street, Quesnel, BC V2J 5K7, Canada.

\section{Received: 21 July 2016 Accepted: 25 August 2017}

Published online: 04 October 2017

\section{References}

1. Hirdes JP. Addressing the health needs of frail elderly people: Ontario's experiences with an integrated health information system. Age. Aging. 2006:35:329-31.

2. Carpenter I, Hirdes J. Using interRAI assessment systems to measure and maintain quality of long-term care. In: Organisation for economic cooperation and development (OECD). A good life in old age? Monitoring and improving quality in long-term care; 2013. p. 93-139.
3. Council of the European Union. Social protection committee and the European Commission services. In: Adequate social protection for longterm care needs in an ageing society; 2014.

4. Canadian Institute for Health Information $[\mathrm{CH} H \mathrm{I}]$. Health Care in Canada 2011: A Focus on Seniors and Aging 2011. https://secure.cihi.ca/free_ products/HCIC_2011_seniors_report_en.pdf. Accessed 09 May 2016.

5. Fry PS. Whose quality of life is it anyway? Why not ask seniors to tell us about it? Int J Aging Hum Dev. 2000;50:361-83.

6. Wilson DM. End-of-life care preferences of Canadian senior citizens with caregiving experience. J Adv Nurs. 2000;31:1416-21.

7. Canadian Institute for Health Information [CIHI]. Residential Care: Types of Care. 2016. https://www.cihi.ca/en/types-of-care/community-care/residentialcare. Accessed 09 May 2016

8. Kane RL, Kane RA. What older people want from long-term care, and how they can get it. Health Aff. 2001:20:114-27.

9. Terrell KM, Miller DK. Challenges in transitional care between nursing homes and emergency departments. J Am Med Dir Assoc. 2006;7:499-505.

10. Kane RA. Long-term care and a good quality of life bringing them closer together. Gerontologist. 2001:41:293-304.

11. Metlife Market Survey of Nursing Home and Home Care Costs. 2004. http:// www.MatureMarketInstitute.com. Accessed 09 May 2016.

12. Miller NA, Harrington C, Goldstein E. Access to community-based long-term care: Medicaid's role. J Aging Health. 2002;14:138-59.

13. Neufeld E, Freeman S, Joling K, Hirdes JP. "When the golden years are blue": changes in depressive symptoms over time among older adults newly admitted to long-term care facilities. Clin Gerontol. 2014;37:298-315.

14. Freeman S, Spirgiene L, Martin-Khan M, Hirdes JP. Relationship between restraint use, engagement in social activity, and decline in cognitive status among residents newly admitted to long-term care facilities. Geriatr Gerontol Int. 2016; https://doi.org/10.1111/ggi.12707.

15. Boling PA, Parsons P. A research and policy agenda for transitions from nursing homes to home. Home Health Care Serv Q. 2007:26:121-31.

16. Hurd MD, Michaud P, Rohwedder S. The lifetime risk of nursing home use. In: Wise DA, editor. Discoveries in the economics of aging. University of Chicago Press; 2014. p. 81-114

17. Newman HN. Medicare and Medicaid. Ann Am Acad Pol Soc Sci. 1972;399: $114-24$.

18. Hirdes JP, Mitchell L, Maxwell CJ, White N. Beyond the 'iron lungs of gerontology': using evidence to shape the future of nursing homes in Canada. Can J Aging. 2011:30:371-90.

19. Kralik D, Visentin K, Van Loon A. (2006). Transition: a literature review. J Adv Nurs. 2006:55:320-9.

20. National Transitions of Care Coalition [NTOCC]. Improving Transitions of Care: The vision of the National Transitions of Care Coalition. 2008. http://www. ntocc.org/Portals/0/PDF/Resources/PolicyPaper.pdf. Accessed on 09 May 2016.

21. Coleman EA. Falling through the cracks: challenges and opportunities for improving transitional care for persons with continuous complex care needs. J Am Geriatr Soc. 2003;51:549-55.

22. Kripalani S, Jackson AT, Schnipper JL, Coleman EA. Promoting effective transitions of care at hospital discharge: a review of key issues for hospitalists. J Hosp Med. 2007;2:314-23.

23. Greenwald JL, Denham CR, Jack BW. The hospital discharge: a review of a high risk care transition with highlights of a reengineered discharge process. J Patient S. 2007;3:97-106.

24. Reid RC, Cummings GE, Cooper SL, Abel SL, Bissell $\perp$, Estabrooks CA, et al. The older persons' transitions in care (OPTIC) study: pilot testing of the transition tracking tool. BMC Health Serv Res. 2013;13:515.

25. Arksey H, O'Malley L. Scoping studies: towards a methodological framework. Int J Soc Res Meth. 2005:8:19-32.

26. Graessel E, Schmidt R, Schupp W. Stroke patients after neurological inpatient rehabilitation: a prospective study to determine whether functional status or health-related quality of life predict living at home 2.5 years after discharge. Int J Rehabil Res. 2014;37:212-9.

27. Poole DL, Duvall D, Wofford B. Concept mapping key elements and performance measures in a state nursing home-to-community transition project. Eval Program Plan. 2006;29:10-22.

28. Robinson J, Porter M, Shugrue N, Kleppinger A, Lambert D. Connecticut's 'money follows the person' yields positive results for transitioning people out of institutions. Health Aff (Millwood). 2015;34:1628-36.

29. Seekins T, Ravesloot C, Katz M, Liston B, Oxford M, Altom B, et al. Nursing home emancipation: a preliminary study of efforts by centers 
for independent living in urban and rural areas. Disabil Health J. 2011:4:245-53.

30. Thorn SH, Pittman A, Myers RE, Slaughter C. Increasing community integration and inclusion for people with intellectual disabilities. Res Dev Disabil. 2009;30:891-901.

31. Winkler D, Farnworth L, Sloan S, Brown T. Moving from aged care facilities to community-based accommodation: outcomes and environmental factors. Brain Inj. 2011;25:153-68.

32. Young L. Community and cluster centre residential services for adults with intellectual disability: long-term results from an Australian-matched sample. J Intellect Disabil Res. 2006;50:419-31.

33. Aaland MO, Leffers $K$, Hlaing T. Discharging to a nursing home: not a terminal event - a follow-up study of senior motor vehicle crash patients. Am Surg. 2006;72:815-9.

34. Brown EL, Raue PJ, Mlodzianowski AE, Meyers BS, Greenberg RL, Bruce ML. Transition to home care: quality of mental health, pharmacy, and medical history information. Int J Psychiatry Med. 2006;36:339-49.

35. Chen YM, Berkowitz B. Older adults home- and community-based care service use and residential transitions: a longitudinal study. BMC Geriatr. 2012;12:44.

36. Gassoumis ZD, Fike KT, Rahman AN, Enguidanos SM, Wilber KH. Who transitions to the community from nursing homes? Comparing patterns and predictors for short-stay and long-stay residents. Home Health Care Serv Q. 2013;32:75-91.

37. Gozalo P, Leland NE, Christian TJ, Mor V, Teno JM. Volume matters: returning home after hip fracture. J Am Geriatr Soc. 2015;63:2043-51.

38. Holup AA, Gassoumis ZD, Wilber KH, Hyer K. Community discharge of nursing home residents: the role of facility characteristics. Health Serv Res. 2015; https://doi.org/10.1111/1475-6773.12340.

39. Howell $S$, Silberberg M, Quinn WV, Lucas JA. Determinants of remaining in the community after discharge: results from New Jersey's nursing home transition program. Gerontologist. 2007;47:535-47.

40. Martikainen P, Moustgaard H, Murphy M, Einiö EK, Koskinen S, Martelin T, et al. Gender, living arrangements, and social circumstances as determinants of entry into and exit from long-term institutional care at older ages: a 6year follow-up study of older Finns. Gerontologist. 2009;49:34-45.

41. Meador R, Chen E, Schultz L, Norton A, Henderson C, Pillemer K. Going home: identifying and overcoming barriers to nursing home discharge. Care Manag J. 2011;12:2-11.

42. Mudrazija S, Thomeer MB, Angel JL. Gender differences in institutional longterm care transitions. Womens Health Issues. 2015;25:441-9.

43. Spirgiene L, Routasalo PE, Macijauskiene J. Resources of residents for potential transition from long-term care to community. Med Lith. 2013;49:522-8.

44. Thomas KE, Gassoumis ZD, Wilber KH. Conversion diversion: participation in a social HMO reduces the likelihood of converting from short-stay to longstay nursing facility placement. J Am Med Dir Assoc. 2010;11:333-7.

45. Toles M, Anderson RA, Massing M, Naylor MD, Jackson E, Peacock-Hinton S, et al. Restarting the cycle: incidence and predictors of first acute care use after nursing home discharge. J Am Geriatr Soc. 2014;62:79-85.

46. Wodchis WP, Teare GF, Naglie G, Bronskill SE, Gill SS, Hillmer MP, et al. Skilled nursing facility rehabilitation and discharge to home after stroke. Arch Phys Med Rehabil. 2005;86:442-8.

47. Wysocki A, Kane RL, Dowd B, Golberstein E, Lum T, Shippee T. Hospitalization of elderly medicaid long-term care users who transition from nursing homes. J Am Geriatr Soc. 2014;62:71-8.

48. Callahan CM, Arling G, Tu W, Rosenman MB, Counsell SR, Stump TE, et al. Transitions in care for older adults with and without dementia. J Am Geriatr Soc. 2012;60:813-20.

49. Arling G, Abrahamson KA, Cooke V, Kane RL, Lewis T. Facility and market factors affecting transitions from nursing home to community. Med Care. 2011:49:790-6.

50. Arling G, Kane RL, Cooke V, Lewis T. Targeting residents for transitions from nursing home to community. Health Serv Res. 2010;45:691-711.

51. Arling G, Williams AR, Kopp D. Therapy use and discharge outcomes for elderly nursing home residents. Gerontologist. 2000;40:587-95.

52. Bardo AR, Applebaum RA, Kunkel SR, Carpio EA. Everyone's talking about it, but does it work? Nursing home diversion and transition. J Appl Gerontol. 2014;33:207-26.

53. Delate T, Chester EA, Stubbings TW, Barnes CA. Clinical outcomes of a home-based medication reconciliation program after discharge from a skilled nursing facility. Pharmacotherapy. 2008;28:444-52.
54. Fries $\mathrm{BE}$, James $\mathrm{ML}$. Beyond section Q: prioritizing nursing home residents for transition to the community. BMC Health Serv Res. 2012;12:186.

55. McCarthy JF, Szymanski BR, Karlin BE, Katz IR. Suicide mortality following nursing home discharge in the department of veterans affairs health system. Am J Public Health. 2013;103:2261-6.

56. Naomi A, Shiroiwa T, Fukuda T, Murashima S. Institutional care versus home care for the elderly in a rural area: cost comparison in rural Japan. Rural Remote Health. 2012;12:1817.

57. Newcomer R, Kang T, Graham C. Outcomes in a nursing home transition case-management program targeting new admissions. Gerontologist. 2006:46:385-90.

58. Nishita CM, Wilberk H, Matsumoto S, Schnelle JF. Transitioning residents from nursing facilities to community living: who wants to leave? J Am Geriatr Soc. 2008;56:1-7.

59. Penrod JD, Kane RA, Kane RL. Effects of post-hospital informal care on nursing home discharge. Res Aging. 2000;22:66-82.

60. Marcum ZA, Hardy SE. Medication management skills in older skilled nursing facility residents transitioning home. J Am Geriatr Soc. 2015;63:1266-8.

61. Graham C, Anderson L, Newcomer R. Nursing home transition: providing assistance to caregivers in transition program. Prof case Man. 2005;10:93-101.

62. Anderson RM. Revisiting the behavioral model and access to medical care: does it matter? J Health Soc Behav. 1995:31:1-10.

63. Anderson R, Newman JF. Societal and individual determinants of medical care utilization in the United States. Milbank Mem Fund Q Health Soc. 1973;51:95-124.

64. Trochim WMK. An introduction to concept mapping for planning and evaluation. Eval Program Plann. 1989;18:143-53.

65. Roberts K, Taykor B. Nursing research processes: an Australian perspective. Nelson: Melbourne; 1998.

66. Carr DD. Case managers optimize patient safety by facilitating effective care transitions. Prof Case Manag. 2007;12:70-80.

67. Sminkey PV, LeDoux J. Case management ethics: high professional standards for health Care's interconnected worlds. Prof case manag. 2016;21:193-8.

68. Kane RA, Degenholtz HB, Kane RL. Adding values: an experiment in systematic attention to values and preferences of community long-term care clients. J Gerontol B Psychol Sci Soc Sci. 1999:54:S109-19.

69. Koivumaa-Honkanen H, Honkanen R, Viinamaeki H, Heikkilae K, Kaprio J, Koskenvuo M. Life satisfaction and suicide: a 20-year follow-up study. Am J Psychiatry. 2001;158:433-9.

70. Gornick M, Greenberg JN, Eggers PW, Dobson A. Twenty years of Medicare and Medicaid: Covered populations, use of benefits, and program expenditures. Health Care Financ Rev. 1985;Suppl:13-59.

71. Mossialos E, Wenzl M, Osborn R, Anderson C, editors. 2014 International Profiles of Health Care Systems. The Commonwealth Fund. 2015. http:// www.commonwealthfund.org/ /media/files/publications/fund-report/2015/ jan/1802_mossialos_intl_profiles_2014_v7.pdf. Accessed 09 May 2016.

72. Canadian Institutes of Health Research [CIHR]. Canada's strategy for patient oriented research. Ottawa, ON: Canadian Institutes of Health Research. 2011. http://www.cihr-irsc.gc.ca/e/documents/P-O_Research_Strategy-eng.pdf. Accessed on 09 May 2016.

\section{Submit your next manuscript to BioMed Central and we will help you at every step:}

- We accept pre-submission inquiries

- Our selector tool helps you to find the most relevant journal

- We provide round the clock customer support

- Convenient online submission

- Thorough peer review

- Inclusion in PubMed and all major indexing services

- Maximum visibility for your research

Submit your manuscript at www.biomedcentral.com/submit
Biomed Central 